\title{
Hydraulic method to determine the ecological flow for fish
}

\author{
YAN Jun ${ }^{1}$, FU Xuewei ${ }^{1}$, TIAN chengwei ${ }^{2}$, YANG Zhenyu ${ }^{2}$ and LIU Qingyan ${ }^{1}$ \\ ${ }^{1}$ North China University of Water Resources and Electric Power, Henan, Zhengzhou,450011; \\ ${ }^{2}$ Hydrology Bureau of Fuzhou City, Jiangxi, Fuzhou,344000
}

\begin{abstract}
Social and economic development will influence the nature environment and lead to ecological problems, among which the ecological flow concerns the food chain and fish populations. Although there are many computation formulas for counting ecological flow, it is very difficult to unite and get reasonable values. According to the existing research of ecological flow, the concept and calculation method of ecological flow are analyzed, which shows that in a complex ecological system, ecological water requirement is difficult to meet the requirements of all the protection object of water requirement at the same time. Therefore, we should focus on the specific fish with reference value to build ecological protection object and determine the ecological flow. Furthermore, the ecological flow should be the regulation of water quality and water quantity in time and space. Using hydraulic method, the fish living space under different water flow environments can be determined, and specific time and space regulation schemes can be obtained.
\end{abstract}

\section{Introduction}

In recent years, people have become increasingly aware that the changes in the hydrological process have an important impact on maintaining the balance of the ecosystem (Cheng, 2005). The precondition for maintaining the normal development and construction of ecological environment must be the basic guarantee of ecological environment water demand. At present, the research on ecological environment water demand is still in the preliminary stage of development, and the research on this aspect is relatively weak. At the same time, due to the difference among the calculation methods, the accuracy of ecological water demand will be directly affected, and various strategic strategies for the sustainable development of human and nature will also be affected. Therefore, it is of great theoretical and engineering significance to unify the accurate formula to calculate the ecological flow and explore suitable management strategies for ecological environment construction and rational allocation for water resources.

\section{Concepts of ecological flow}

Many scholars have carried out studies on ecological flow, as shown in Table 1.

Table 1 Concepts of ecological flow

\begin{tabular}{|c|l|}
\hline Scholar & \multicolumn{1}{c|}{ Research results } \\
\hline $\begin{array}{c}\text { WANG et al. } \\
\text { (Wang, 2002) }\end{array}$ & $\begin{array}{l}\text { Ecological water demand is water used to maintain ecosystem stability, natural } \\
\text { ecological protection and ecological construction. As to the primary productivity } \\
\text { without the require water for plant system, such as river sand transportation, } \\
\text { diluting pollutants, ground subsidence control water, it can be named as the } \\
\text { environmental water requirement. }\end{array}$ \\
\hline $\begin{array}{c}\text { XU \& YANG] } \\
\text { (Xu, 2003) }\end{array}$ & $\begin{array}{l}\text { Ecological water demand is the amount of water needed by an ecosystem to reach } \\
\text { a certain ecological level or maintain a certain ecological balance, or the amount } \\
\text { of water needed to perform the desired ecological function. The water allocation is } \\
\text { reasonable and sustainable. For a particular ecosystem, its ecological water demand } \\
\text { has a threshold range, with both upper and lower limits. Exceeding the upper and } \\
\text { lower limits will lead to the degradation and destruction of the ecosystem. }\end{array}$ \\
\hline $\begin{array}{c}\text { XIA \& Feng } \\
\text { Xia, 2002 \& Xia, }\end{array}$ & $\begin{array}{l}\text { Ecological water demand is based on the concept of hydrological cycle. From the } \\
\text { perspective of maintaining the survival and ecological functions of the ecosystem, } \\
\text { it is the objective water demand under a certain ecological environment. Ecological } \\
\text { water demand can be understood as the minimum water resource demand that }\end{array}$ \\
\hline
\end{tabular}




\begin{tabular}{|c|c|}
\hline & $\begin{array}{l}\text { cannot be occupied by maintaining certain ecosystem functions, including natural } \\
\text { ecology and artificial ecology. }\end{array}$ \\
\hline $\begin{array}{l}\text { LIU et al. } \\
\text { ( Liu, } 2002 \text { \& Liu, } \\
\text { 2007) }\end{array}$ & $\begin{array}{l}\text { The ecological water demand of rivers is not a simple addition of water } \\
\text { complement between species and nature, but should be determined and analyzed } \\
\text { according to their mutual relations. He also defined the concept of ecological } \\
\text { velocity and ecological hydraulic radius, and proposed a hydraulic method that } \\
\text { takes into account river information (hydraulic radius, roughness, hydraulic } \\
\text { gradient) and river velocity needed to maintain a certain ecological function. From } \\
\text { the point of view of the coordinated development of water resources exploitation } \\
\text { and utilization and ecological environment, four principles of water and heat } \\
\text { energy balance, water and salt balance, water and sediment balance and regional } \\
\text { water supply and demand balance are put forward for the calculation of ecological } \\
\text { water demand. }\end{array}$ \\
\hline $\begin{array}{l}\text { YAN et al. } \\
\text { (Yan, 2007) }\end{array}$ & $\begin{array}{l}\text { The water requirement of the ecological environment of river system should } \\
\text { include the two aspects of water quality and quantity, or the reasonable quantity of } \\
\text { water under certain water quality requirement. According to the spatial structure of } \\
\text { river system, it can be divided into three categories: water requirement for } \\
\text { maintaining physical structure of river, water requirement for evaporation of water } \\
\text { surface and ecological water requirement for floodplain. The ecological water } \\
\text { demand of rivers should be the unity of water quantity and water quality: sufficient } \\
\text { water quantity is the necessary condition to maintain the health of river ecosystem, } \\
\text { and the qualified water quality is the guarantee of the ecological function of water } \\
\text { volume. }\end{array}$ \\
\hline
\end{tabular}

These results indicate that there is still a lack of unified and standard definition and perfect theory in the study of ecological water demand at present, and the definition of such concepts as ecological flow, ecological water demand and environmental water demand is still unclear, and no unified concept and connotation have been formed. In fact, the hydrological process of rivers is the change process of the size and frequency of ecological environmental flow. Different flow processes have different ecological and environmental functions. The process of ecological environment flow includes water quantity, water quality, water purification and nutrient transport. The continuous decrease of weak flow will lead to decreased water connectivity, change of river habitat, the transport of nutrients, migration and reproduction of aquatic organisms are all affected, and the function of water ecosystem is reduced. When runoff is reduced to or even below the minimum ecological flow, the hydrological connectivity is lost and the ecological pattern of the river system will be changed. If the flow continues to decrease until the flow stops, the river becomes dry and the ecosystem is completely destroyed, aquatic life may become extinct. The ecological flow should be the water quantity needed to maintain the stable balance of river ecosystem. Environmental flow refers to the amount of water needed to meet the basic environmental function of rivers, protect and improve human water environment. The ecological flow should include the requirements on water quality and water quantity, which are variables that vary with time and place, and are closely related to the goals of ecological environmental protection. Ecological flow is not a specific value but an interval, and its lower limit is the minimum ecological flow, which is used to maintain the basic ecological environment function of rivers. The minimum eco-environmental water demand of river course refers to the minimum amount of water that must flow in river course all year round to maintain the most basic environmental function of river.

\section{Ecological flow calculation method}

River ecological flow assessment methods can be divided into four types: 1ook-up tables, desk-top analysis, functional analysis and hydraulic habitat modeling. Hydrology has the largest proportion of river ecological flow determination methods accounting for about $30 \%$ of the total types. There are 61 calculation methods, mainly concentrated in the first three categories. Most methods are still in use. According to statistics by WANG, there are 207 different calculation methods for ecological flow (WANG, 2007).The results of nearly five years of research related to specific fish habitats are as follows:

ZHU pointed out that the oviposition from Yichang to Chenglingji (middle reach of Yangze River) was affected by the slow down flow, the disappearance of flood peak and the low water temperature (Zhu, 2013). Based on the measurement and analysis of the flow field of the four big domestic fish spawning grounds in the middle reaches of the Yangtze River, based on the statistical and spatial analysis methods, the characteristics of ecological hydraulics of the spawning grounds were quantitatively described. Using the theory of vorticity, the characteristics of cross section mean vorticity of typical spawning field was studied, and the flow and section average vorticity was analyzed. The characteristics of spatial variation were analyzed and studied. It is found that the variation of flow rate is the necessary but not sufficient condition for the oviposition of the four largest fish, and the numerical distribution of velocity is not the necessary and sufficient condition to distinguish the spawning field from the nonoviposition period. The spatial variation distribution characteristics of the cross section mean vorticity value can be used as the hydraulics indicator of the oviposition in the middle reaches of the Yangtze River to some extent. In the middle reach of the Yangtze River, the main distribution range of the cross section mean vorticity value of the four big domestic fishes in the spawning farm is 
about $0.237 \sim 0.2652 \mathrm{~s}^{-1}$. The average vorticity value of cross-section is positively correlated with the flow velocity. But this positive correlation is not necessarily linear. The spatial variation characteristics of the mean vorticity of the cross section can show the difference between the oviposition and the non-ovipositing field.

GONG studied the swimming ability and swimming behavior of juvenile $5.0 \sim 15.0 \mathrm{~cm}$ grass carp by using a self-made fish swimming behavior test device (Gong, 2015). It was found that the critical swimming speed of juvenile grass carp within this body length range was between $68-100 \mathrm{~cm} / \mathrm{s}$. The critical swimming speed increases linearly with the increase of fish body length, and the maximum velocity in the four stages of swimming is $45.6 \%, 82.8 \%, 95.9 \%$ and $100 \%$ of the critical swimming speed respectively.

MO used FLOW3D software to establish a threedimensional hydrodynamic model (Mo, 2016). Through correlation analysis and curve fitting, he found that the sensitive factors of fish habitat in Daban River were $\mathrm{pH}$ of water temperature, chlorophyll A, velocity and depth of water. The habitat suitability curve of each sensitive factor was established with the fish density as the evaluation index. The Habitat Suitability Index (HIS) was a continuous value of $0 \sim 1$. Based on the compensatory effect of various sensitive factors considered by IFIM method, the geometric average method was used to put forward the HSI Model under three different application background of fish habitat suitability of Daban River. The value of HSI is also the continuous value between 0 and 1 . According to the HSI value, the fish habitat can be divided into five categories, which are unsuitable for survival, poor, general, good and best. The model was verified by the monitoring data of the middle and lower water bodies in 2015, and it was found that the higher the habitat fitness value was, the higher the fish density was.

Using the method of Canonical Correspondence Analysis (CCA), GAO analyzed the relationship between the fish eggs density of the main breeding groups and the hydrological environmental factors on the sampling section (Gao, 2016). He found that the breeding quantity of most groups was related to the river water flow, the diurnal change of discharge, and the water temperature. Transparency and other environmental factors were significantly correlated, in which the breeding of the genus Misgurnus needed higher water temperature and flow rate, and the reproduction of the four kinds of main domestic fish required higher requirements for flux and flux changes, and the breeding habits of the minnow fish had great differences. The results of Generalized Additive Model (GAM) analysis show that the spawning of copper fish is related to transparency, dissolved oxygen, conductivity, flow rate and other factors. There was no significant correlation between water temperature and $\mathrm{pH}$ and daily flow rate $(\mathrm{P}<0.01)$, but there was a significant correlation between egg laying and transparency $(\mathrm{P}<0.01)$ and water temperature $(\mathrm{P}<0.05)$.

SHUAI analyzed the breeding ecology of bighead carp in the study area based on the long-time series larva data and daily average flow data from 2006 to 2013, and the relationship between the runoff and the abundance of larval bighead carp by the method of Cross Wavelet
Analysis (Shui, 2016). He found that the occurrence of early bighead carp resources in the Pearl River system was mainly from May to August 2006 to 2011, and the amount of supplementary resources gradually decreased during the period of 2012-2013, while the annual occurrence time of early bighead carp resources showed a decreasing trend, in which the maximum reproduction amount was observed. The time of appearance is advanced year by year. The results of interactive wavelet spectrum analysis showed that the change of runoff was positively correlated with the abundance of bighead carp larvae. When the runoff was more than $5 \times 10^{3} \mathrm{~m}^{3} / \mathrm{s}$ and lasted for more than 2 days, it was the basis of mass reproduction of bighead carp in Pearl River.

MENG et al. established a conceptual model between ecological demand and flow rate of long-snout catfish, which is chose as the protection target in the main stream of Huaihe River (MENG, 2016). The ecological environment of Leiocephala longirostris was analyzed before and after the hydrological variation. The flow combination suitable for the growth and reproduction of Leiocephala longirostris was determined. He found that the high pulse flow before mutation is of long duration and appropriate time, and the frequency of flood after mutation is increased, and the flow before mutation is more suitable for the growth and reproduction of long snout catfish, and it is more suitable for the growth and reproduction of long snout catfish at each stage of its growth and reproduction. The flow conditions before mutation were better than those after mutation. The suitable discharge in spawning period is $545-1212 \mathrm{~m}^{3} / \mathrm{s}$, more than $1750 \mathrm{~m}^{3} / \mathrm{s}$ in the feeding period of juvenile fish and larger than $74 \mathrm{~m}^{3} / \mathrm{s}$ in the wintering period.

In a word, the evaluation of the ecological environment of the river is complex and comprehensive, and the research of the method of ecological flow is basically in the stage of qualitative analysis and macroscopic quantitative analysis. The river ecosystem is a dynamic and complex system, including various factors and conditions, such as river form, hydrological situation, biological species characteristics, human activity influence, etc. Therefore, the ecological environment demand is affected by natural change and human activity, while the interaction between various systems, especially the transformation of water and the contact of the ecological environment, is lack of in-depth research. To calculate the ecological protection of the river, the ecological protection objects that need to be considered are aquatic fish, water animals, and the plants that grow on the bank, especially endangered or precious species, river water quality, etc. In this complex river ecosystem, it is difficult to calculate the water requirements of all protected objects at the same time. Therefore, we can only choose the important objects which have significant values to establish the ecological protection target system, and determine the interval and value of its ecological flow. To determine the ecological flow, we have to define the target protect object, the space-time scale, the water quality index, and consider the competitive relationship between the ecological water and the economic society. The regulation of ecological flow should be the regulation of water quality and water amount in specific temporal and 
spatial range. The hydraulic method can be used to determine the survival space of fish in different water currents, the physical model and the mathematical model of the protected object of the reserve domain can be used to obtain the concrete time and time control scheme.

\section{Hydraulic method}

Hydraulic method can be used to determine the inrush velocity, the appropriate velocity of flow and the flow field and process in the protected area for the protection object which can define various control indexes for fish survival under different water environment conditions.

\subsection{Main technical indicators}

Induction velocity. It is also known as incipient velocity and starting velocity and which refers to the flow velocity values that fish just can produce currenttending reaction. The measurement of induction velocity is of great significance. For example, the construction of fishpass and the high density fish culture in reservoir. If the velocity of the main stream in the fishpass chamber is too small and less than the induction velocity, the fish will not be able to sense the direction of the main stream and move or wander in the pond chamber.

Critical velocity. It refers to the boundary between durable speed and sustained speed for the fish and which is used to investigate on maximum sustained swimming ability of fish.

Continuous velocity. It indicates that the fish can maintain the flow velocity of a certain swimming state exceeding 200minute.

Inrush velocity. It is also known as the limit velocity that refers to the fish swimming behavior when passing through the high-speed water flow speed value which is the maximum velocity that fish can overcome.

\subsection{Preparation before testing}

Divide the fishes into 3 groups with 5 tails in each group. Before the test, stop feeding fish and place the domesticated tank in the shade for 24 hours. Control the water temperature at $(26 \pm 2)^{\circ} \mathrm{C}$ and oxygenate 24 hours. Add light shield to avoid the interference of external light. Avoid the interference of other sound during the test.

Induction Velocity test. In the test, the fish can be selected randomly in the U-shaped test flume for 5 minutes until the fish had no sudden diversion swimming behavior. Starting dynamo gradually increases the frequency to adjust the water flow velocity in the flume until the minimum water flow velocity when the fish adjusts the direction of the body to start the top flow then the water flow velocity is regarded as the induced velocity of the fish.

Critical Velocity test. Measure the critical velocity by the "incremental velocity method". The fish is forced to move in a tank with incremental velocity until it is exhausted. Firstly, carry out three preliminary tests, through which the fish can be selected and put into the test section for preliminary test. Before the test, the fish can be adapted to small velocity for 1 hour and then the velocity is increased by $10 \%$ every 2 minutes until the fish is too tired to swim. The average velocity obtained from the three preliminary tests can be taken as the prediction of the critical velocity for the formal test which reference resources. The criterion for testing fatigue of fish is that the test fish is washed down to the downstream and cannot swim for more than 20s. Secondly, operate the formal test. Place the fish in the test section to adapt to $20 \%$ of flow rate for 1 hour to eliminate the stress of the transfer process on the fish. At the beginning of the test, the critical velocity was increased by $5 \%$ to $60 \%$ every 5 minutes and then increased by $10 \%$ every 20 minutes. At the same time, the swimming behavior of the fish can be observed and recorded until the fish is tired and could not swim continuously. At this time, record the water speed and swimming time. Therefore, the critical velocity can be estimated, the length and weight of the tested fish can be recorded.

Continuous Velocity test. After measuring the critical velocity of the fish, according to a certain multiple or fraction of the speed, set different detection speeds and then adopt the fixed velocity method which is keeping the set velocity stable to measure the time during which the fish can maintain swimming. The continuous swimming speed can be determined if the swimming speed is maintained for more than 200 minute at the set speed.

Inrush Velocity Test. Because of fish swim at high speed in a "burst-slip" swimming mode, the speed of the inrush maintains very short time so the image analysis method can be used to estimate the inrush velocity.

\section{Conclusion}

By measuring various velocities under different flow environments and combining the mathematical model of the protected area, the ecological flow can be determined based on the target fish in a specific and regulated living environment of different concerning species in the food chain. Finally, the protection of species and the improvement of ecological environment can be realized.

\section{Acknowledgments}

This work was supported by Natural Science Foundation of Henan Province (U170410545), the National Natural Science Foundation of China (51779096) and the Major Science and Technology Projects of Water Conservancy of Jiangxi Province, such as "Multi level linkage study of basin and reservoir for water ecological civilization (KT201508)", "Major spatial pattern and evolution characteristics of water ecological civilization in Poyang Lake Basin (KT201411)" and "Research on evolution law of water cycle in Fuhe River basin based on distributed binary water cycle model (KT201501)".

\section{Reference}

1. CHENG Shenyu, LIU Baoqin. Actuality and Progress of Water Requirement Study on Ecological 
Environment. Water Science and EngineeringTechnology. 2005,6:39-41.

2. FENG Huali, XIA Jun, ZHAN Chesheng. Advances on Ecological and Environmental Water Requirement Research.Progress in Geography. 2003, 22 (6):591598.

3. GAO Tianheng. Studies on Gobioninae fish resources and habitat selections in the upper Yangtze River. Doctoral dissertation. 2016.

4. GONG Li, WU Yihong, BAIYIN Baoligang, MU Xiangpeng. Experimental study on swimming capability and swimming behavior of juvenile grass carp. Journal of China Water Conservancy and Hydropower Research. 2016,6(3): 211-216.

5. LIU Changming. The concept and importance of ecological water demand. The Impact of Science on Society. 2002,2:25-29.

6. LIU Changming, MENG Baohui, SONG Jinxi. Ecological hydraulic radius method of ecological water demand estimation in river channel. Progress in Natural Science. 2007,17 (1):42-48.

7. MENG Yu, ZHANG Xiang, XIA Jun. Definition of environmental flow components for Leiocassis Longirostris in the Huai River considering habitat change and hydrological change. Journal of Hydraulic Engineering. 2016,5:626-634.

8. MO Weijun. Study on the fish habitat status of tributary Dabang river of Beipan river. Master's thesis. 2016.

9. SHUAI Fangmin, LI Xinhui, LI Yufei, YANG Jiping, LI Jie. Analysis of the ecohydrological demands of bighead carp breeding in the Dongta spawning grounds of the Pearl River, via cross-wavelet analysis. Acta Ecologica Sinica. 2016, 36(19): 6071-6078.

10. WANG Fang, LIANG Ruiju,YANG Xiaoliu,CHEN Minjian. A study of ecological water requirements in northwest China I : theoretical analysis.Journal of Natural Resources. 2002, 17 (1):1-8.

11. XIA jun, ZHENG dongyan, LIU Qinge. Study on Evaluation of Eco-water Demand in Northwest China. Hydrology. 2002, 22 (5):12-17.

12. XU Xinyi, YANG Zhifeng. General Discussion on Ecological Environmental Water Demand. Water Resources Planning and Design. 2003 (1):21-26.

13. YAN Denghua, WANG Hao, WANG Fang, TANG Yun. Frame of research work on ecological water demand and key topics. Journal of Hydraulic Engineering. 2007, 38 (3):267-273.

14. ZHU Zhengwei. Research on the Spatial variability of eco-hydraulic characteristics of four famous Chinese carps'important spawning grounds in the middle reach of the Yangtze River. Master's thesis. 2013. 